\title{
Study of a New Passive Magnetic Levitation Concept
}

\author{
Richard F. Post
}

Lawrence Livermore National Laboratory

Livermore, California

March, 1995

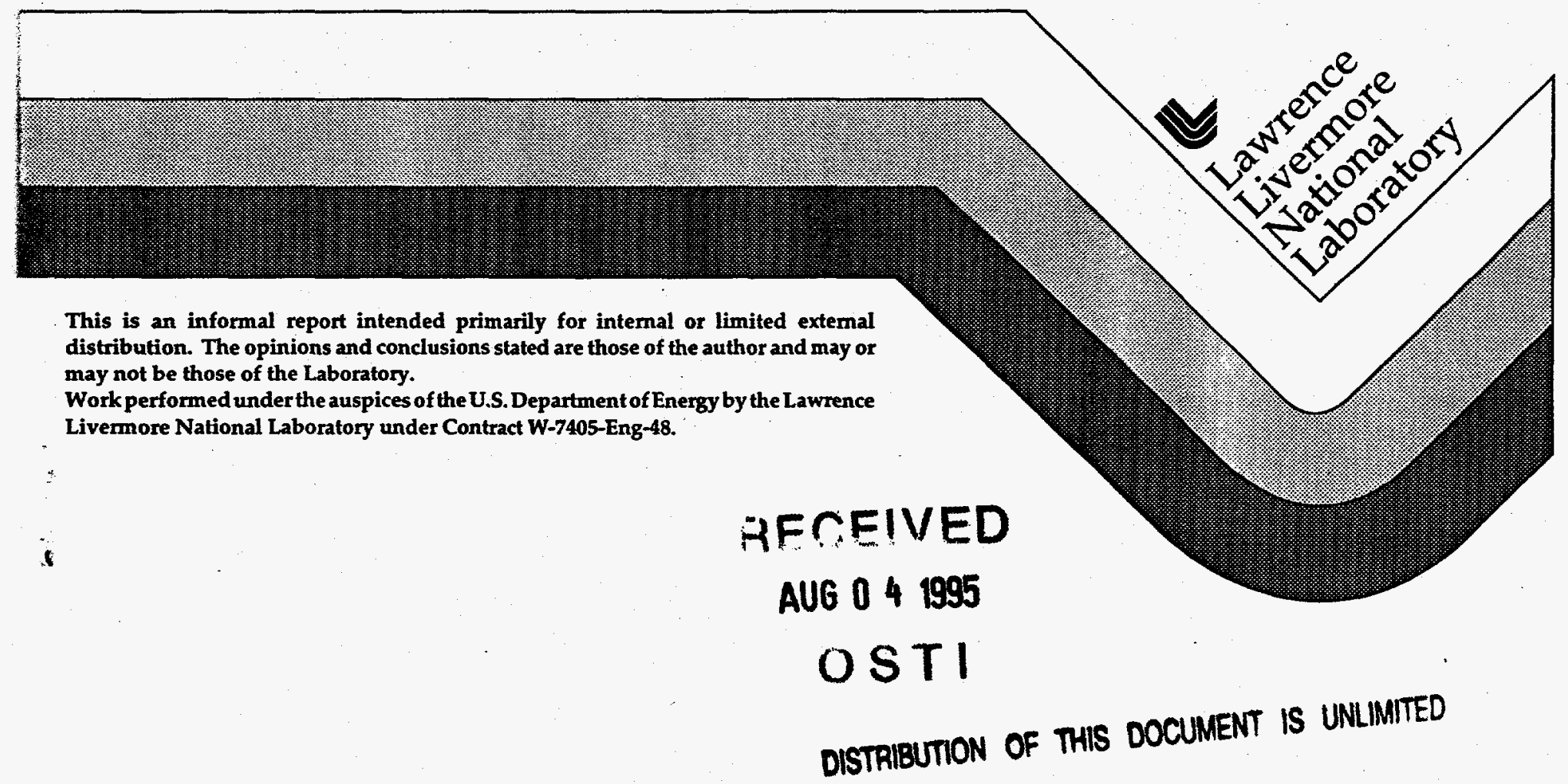




\section{DISCLAIMER}

This report was prepared as an account of work sponsored by an agency of the United States Government. Neither the United States Government nor any agency thereof, nor any of their employees, make any warranty, express or implied, or assumes any legal liability or responsibility for the accuracy, completeness, or usefulness of any information, apparatus, product, or process disclosed, or represents that its use would not infringe privately owned rights. Reference herein to any specific commercial product, process, or service by trade name, trademark, manufacturer, or otherwise does not necessarily constitute or imply its endorsement, recommendation, or favoring by the United States Government or any agency thereof. The views and opinions of authors expressed herein do not necessarily state or reflect those of the United States Government or any agency thereof. 


\section{DISCLAIMER}

Portions of this document may be illegible in electronic image products. Images are produced from the best available original document. 
FY94 LDRD Project

\section{Study of a New Passive Magnetic Levitation Concept}

Richand F. Post

\section{Introduction and Motivation for the Project}

As a bonus from an existing LDRD-supported project (Electromechanical Battery Research and Development) a new concept for the magnetic levitation of a moving object evolved. To initiate a study of the merits of the concept mid-year "seed money" LDRD funding was provided. The FY94 activities resulted in a preliminary evaluation of the merits of this concept through calculations, laboratory measurements, and the design of a simple test model.

There is now considerable intemational interest in the "Maglev" concept for highspeed trains. Wear, rolling friction, and speed limitations of conventional rail technology make this technology unsuitable for such trains, whence the use of magnetic levitation. In present Maglev trains, however, such as those constructed in Germany and Japan, servocontrolled magnetic systems are required, involving sensor and control circuitry and nontrivial on-board power requirements. In such systems the failure of a control system can have serious consequences, so that redundant systems may be required, thus adding to the cost and complexity.

It would be highly desirable to replace the present "active", servo-controlled magnetic levitation systems with a totally passive one, one for which neither control circuits nor on-board power would be required. Failure of such a system could be made to be much more benign in its consequences than for servo-controlled ones, and the cost, particularly of the on-board equipment, might be greatly reduced.

\section{Technical Aspects}

The concept explored involves the following two main components:

- One or more arrays of permanent magnets on the moving object, producing a spatially periodic magnetic field below the array.

- A "track" made up of a linear array of inductively loaded circuits embedded in the surface of the track. 
If used in a full-sized magnetically levitated train car the operation of the system would be as follows:

At rest ("in the station") no levitation occurs and the train car relies on auxiliary wheels to carry its weight. However, as soon as it is in motion at an appreciable speed the moving magnet array will induce currents in the conductor array and thereby levitate the train. Owing to the inductive loading the drag power can be made to be a small fraction of the power required to overcome aerodynamic friction. Furthermore, theory shows that the levitation mechanism is stable against vertical displacements, independent of speed or load (up to the maximum permitted load of the car). If the driving power fails, the train will simply slow down, and come to rest on its auxiliary wheels as its speed approaches zero. No on-board power or control circuitry is required, and the permanent magnet arrays should have a high degree of reliability.

In the theoretical investigation of the concept a very simple approximate expression for the lift-to-drag ratio of the system was derived. From this expression it can be seen that the drag force actually decreases as the speed increases, by contrast with aerodynamic drag or bearing-friction drag on a conventional train, which always increases with speed. The expression that was derived is as follows:

$$
\frac{\text { Lift }}{\text { Drag }} \approx(\omega \mathrm{L}) / \mathrm{R}
$$

Here $L$ (hy) is the inductance of an individual circuit, $R$ (ohms) is the resistance of the circuit, and $\omega$ is the angular frequency of the exciting wave. This frequency is in turn determined simply from the spatial wavelength of the permanent magnet array and the speed of the train over the track. It is a straightforward matter to adjust the $L / R$ of the circuits so that the lift-to-drag ratio is very large compared to unity at all but the lowest speeds, corresponding to a very low power requirement per kilogram levitated.

A closely related equation to that for the lift-to-drag ratio can be used to calculate the lifting force per Watt of dissipated power. As a typical design number, a levitating parameter of 10 Newtons per Watt could be targeted. This corresponds to a levitating power requirement (derived solely from the motion of the car relative to the track) of about 50 kilowatts for a train car (Grumman Maglev train) weighing 50,000 kilograms and 
requiring 8.3 Megawatts to overcome aerodynamic losses at operating speeds (500 kilometers per hour). The calculated levitating power in this example is thus less than $1 \%$ of the drive power at full speed.

The above technical features of the new concept were deduced from analytical calculations. From this analysis scaling laws were derived that should allow scaling down such a system to a small, "proof-of-principle" model. The work accomplished toward this objective, as described below, was consistent with the limited money and time available in FY94. The project therefore succeeded in its goal of paving the way for the more extensive studies of the concept that are being funded (through LDRD) in FY95.

\section{Summary of work accomplished}

Rather than attempting, on a limited budget, to design an actual long linear track another approach was made: Computations and mechanical designs, including drawings, were made of the following model system. A "track" composed of a close-packed array of inductively loaded circuits arrayed on the outside of a wheel-like structure (diameter of order $0.75 \mathrm{~m}$.) whose axis of rotation is horizontal. By rotating this "track" relative to a stationary "car" the levitating force can be demonstrated simply and directly, this in preparation for building a larger model in which a stationary linear track and a moving car would be used.

By the end of the FY94 funding period the design task for the wheel-track had been completed, and orders were placed for critical components (powdered metal cores for inductive loading). The parameters for these cores were determined from theory. The validity of the theory for this purpose was demonstrated in the measurements by $O$. Richter as described below.

When constructed (in FY95), the "train car" for this model is to be positioned on the top of the wheel, held in place by a lever arm that will be instrumented to measure both the lifting force and the drag that occurs as the track moves beneath the car. At rest the car will be supported by wheels resting directly on the track. As the speed of the rotating track is increased from zero the car will lift off the track, thus simulating the behavior of a moving car levitated above a stationary track.

In parallel with the design of the just-described model, an extensive series of laboratory tests of the force constants between an array of inductively loaded circuits of the 
type to be used, and a Halbach magnet array was undertaken. These tests, carried out during the summer of 1994 by summer-employee Owen Richter, showed close agreement between the theoretically calculated forces and those measured in the laboratory test rig. These measurements and their comparisons with theory are described in an internal report submitted by O. Richter entitled: "Characterization of a Lap Wound, Inductively Coupled Circuit, and Comparison with Theory," dated September 22, 1994. In brief summary of the results, it was found that the theoretical formulae predicted the forces within a few percent over the relevant ranges of the parameters involved.

The upshot of our preliminary look at these new concepts for magnetic levitation is that the concept appears to be a sound one, with experimentally measured circuit force constants showing close agreement with theory. These results were used to make the mechanical design of a "Mark $\Gamma$ " model system, in preparation for the design of a largerscale model to be designed and built in the course of the FY95 LDRD-funded work.

\section{Personnel}

The principal investigator was Richard F. Post. Experimental measurements were carried out by summer-employee Owen Richter, with help in the electrical aspects of the measurements from Gary Dreifuerst. The mechanical design of the model was made by Vern Richmond. Technical advice was also given by Don Bender and Tom Kuklo. 